\title{
Misdiagnosis of Cerebellar Infarctions
}

\author{
Navdeep Sangha, Karen C. Albright, Hui Peng, Farhaan Vahidy, Amelia Boehme, \\ Zhongxue Chen, Sean I. Savitz
}

\begin{abstract}
Background: This retrospective study addresses for the first time the differences in clinical features and outcomes between those individuals with a cerebellar infarct who were correctly diagnosed on initial presentation compared to those who experienced delayed diagnosis. Methods: A retrospective review was conducted of our stroke registry from 09/2003 to 02/2011. Forty seven patients had an isolated cerebellar infarction confirmed by MRI. Misdiagnosis was defined as the diagnosis given by the first physician. Results: Among 47 patients identified, 59.6\% had delayed diagnosis. Five patients in the correct diagnosis group received intravenous tissue plasminogen activator, compared to none in the delayed diagnosis group. Complaints of weakness were protective from delayed diagnosis (OR 0.087, 95\% CI 0.019-0.393, $\mathrm{p}=0.001)$. Conclusion: Patients with an isolated cerebellar infarction need to be considered when patients present with acute non-specific symptoms. Critical components of the neurological examination are omitted which are imperative to diagnose cerebellar infarcts. A thorough neurological examination may increase clinical suspicion of an ischemic stroke.
\end{abstract}

RÉSUMÉ: Erreurs de diagnostic d'infarctus cérébelleux. Contexte: Cette étude rétrospective aborde pour la première fois les différences entre les manifestations cliniques et l'issue clinique chez les individus atteints d'un infarctus cérébelleux lorsqu'un diagnostic exact a été posé au moment de la consultation initiale par rapport à ceux chez qui le diagnostic a été plus tardif. Méthode: Nous avons effectué une revue rétrospective de notre registre de patients atteints d'un accident vasculaire cérébral entre septembre 2003 et février 2011. Quarante-sept patients avaient présenté un infarctus cérébelleux isolé, confirmé par IRM. Le diagnostic posé par le premier médecin qui a examiné le patient a été déterminé comme étant exact ou erroné. Résultats: Le diagnostic a été tardif chez 59,6\% des 47 patients identifiés. Cinq patients dans le groupe chez qui un diagnostic exact avait été posé initialement ont reçu de l'activateur du plasminogène tissulaire et aucun n'en a reçu dans le groupe de patients chez qui le diagnostic a été tardif. Le fait de se plaindre de faiblesse protégeait d'un diagnostic tardif (RC 0,087; IC à 95\% 0,019 à 0,393; p =0,001). Conclusion: Quand des patients consultent pour des symptômes aigus non spécifiques, un diagnostic d'infarctus cérébelleux isolé doit être envisagé. Des éléments essentiels de l'examen neurologique, qui sont indispensables au diagnostic de l'infarctus cérébelleux, sont omis. Un examen neurologique minutieux peut révéler un tableau clinique qui éveille des soupçons quant à la présence d'un accident vasculaire ischémique chez le patient.

Keywords: Stroke, emergency department management, diagnosis, clinical assessment, effectiveness

doi:10.1017/cjn.2014.4

Can J Neurol Sci 2014; 41: 568-571

Cerebellar infarction represents $3 \%$ of all ischemic strokes in the United States, ${ }^{1-3}$ resulting in 27,400 new cerebellar infarctions each year. ${ }^{4}$ An ischemic stroke within the cerebellum presents a clinical and radiological diagnostic challenge. This difficulty may likely be increased in an acute setting where certain components of the neurological examination are often omitted, such as coordination, eye movements and gait. ${ }^{5}$ The initial radiological study of choice to assist in the diagnosis of an acute neurological deficit is often non-contrast computerized tomography (CT) scan. However, in the early hours after the onset of an acute ischemic stroke the CT scan is often negative, ${ }^{6}$ and its sensitivity in the posterior fossa is lower than that of supratentorial ischemic strokes. ${ }^{7}$ Due to the difficulty of rapidly diagnosing a cerebellar stroke, individuals with cerebellar infarction may represent a population of "missed opportunity" for thrombolysis or early preventative interventions to reduce the risk of recurrent stroke. In addition, some cerebellar infarctions progress to pseudotumor edema and brainstem compression, necessitating surgical decompression. A delay in diagnosis may be associated with morbidity and mortality, ${ }^{8}$ but there are no prior studies that have compared patients correctly diagnosed at initial presentation versus those who have a delay in the diagnosis of cerebellar infarction. This cross-sectional study addresses for the first time the differences in clinical features and outcomes between those individuals with a cerebellar infarct who were diagnosed correctly on initial presentation compared with those who initially were misdiagnosed with another medical condition.

\section{Materials AND Methods}

Consecutive patients admitted to the University of Texas Stroke Team from 2003-2011 were screened from our prospective

From the Department of Neurology (NS), Kaiser Permanente, Los Angeles Medical Center, Los Angeles, California; Department of Epidemiology (KCA, AB), School of Public Health, University of Alabama at Birmingham; Health Services and Outcomes Research Center for Outcome and Effectiveness Research and Education (KCA); Center of Excellence in Comparative Effectiveness Research for Eliminating Disparities Minority Health \& Health Disparities Research Center (KCA) Birmingham, Alabama; Stroke Center (HP, ZC, SIS), Department of Neurology, University of Texas Health Science Center at Houston, Houston, Texas.

Received November 26, 2013. Final Revisions Submitted March 26, 2014. Correspondence to: Navdeep Sangha, Department of Neurology, Kaiser Permanente, Los Angeles Medical Center, 1505 N. Edgemont Street, Los Angeles, CA, USA 90027, Email: navdeep.x.sangha@kp.org. 
Table 1: Baseline characteristics, symptoms and signs of patients with isolated cerebellar infarctions who were misdiagnosed and correctly diagnosed.

\begin{tabular}{|c|c|c|c|c|}
\hline & $\begin{array}{l}\text { All Patients } \\
(\mathrm{n}=47)\end{array}$ & $\begin{array}{l}\text { Delayed Diagnosis } \\
\quad(\mathrm{n}=\mathbf{2 8})\end{array}$ & $\begin{array}{l}\text { Correct Diagnosis } \\
\quad(n=19)\end{array}$ & $\begin{array}{c}\mathbf{p} \\
\text { value }\end{array}$ \\
\hline \multicolumn{5}{|l|}{ Baseline characteristics } \\
\hline Age - Mean \pm SD & $57.3 \pm 14.6$ & $56.9 \pm 13.4$ & $57.8 \pm 16.6$ & 0.823 \\
\hline Sex, n (\% Female) & $20 / 47(42.6)$ & $12 / 28(53.6)$ & $5 / 19(26.3)$ & 0.079 \\
\hline Race, $\mathrm{n}$ (\% African American) & $12 / 44(27.3)$ & $7 / 26(26.9)$ & $5 / 18(27.8)$ & 1.000 \\
\hline Baseline NIHSS, Median (Range) IQR & $3(0-20) 0,4$ & $3(0-16), 0,5$ & $2(0-20), 0,4$ & 0.332 \\
\hline Hypertension, n (\%) & $29 / 47(61.7)$ & $16 / 28(57.1)$ & $13 / 19(68.4)$ & 0.435 \\
\hline Diabetes, n (\%) & $15 / 47(31.9)$ & $9 / 28(32.1)$ & $6 / 19(31.6)$ & 0.968 \\
\hline Dyslipidemia, n (\%) & 9/47 (19.1) & $1 / 28(3.6)$ & $8 / 19(42.1)$ & 0.002 \\
\hline Previous stroke / TIA, n (\%) & $10 / 47(21.3)$ & $3 / 28(10.7)$ & $7 / 19(36.8)$ & 0.066 \\
\hline Coronary artery disease, $\mathrm{n}(\%)$ & $7 / 47(14.9)$ & $4 / 28(14.3)$ & $3 / 19(15.8)$ & 1.000 \\
\hline Atrial Fibrillation, n (\%) & $5 / 47(10.6)$ & $3 / 28(10.7)$ & $2 / 19(10.5)$ & 1.000 \\
\hline \multicolumn{5}{|l|}{ Symptoms } \\
\hline Headache, n (\%) & $29 / 47(61.7)$ & $19 / 28(67.9)$ & $10 / 19(52.6)$ & 0.292 \\
\hline Nausea, $\mathrm{n}(\%)$ & $31 / 47(66.0)$ & $21 / 28(75.0)$ & $10 / 19(52.6)$ & 0.112 \\
\hline Vomiting, n (\%) & $26 / 47(55.3)$ & $17 / 28(60.7)$ & $9 / 19(47.4)$ & 0.366 \\
\hline Dizziness, n (\%) & $21 / 47(44.7)$ & $13 / 28(46.4)$ & $8 / 19(42.1)$ & 0.770 \\
\hline Change in speech, $\mathrm{n}(\%)$ & $17 / 47(36.1)$ & $6 / 28(21.4)$ & $11 / 19(57.9)$ & 0.011 \\
\hline Diplopia / Visual Change, n (\%) & 9/47 (19.1) & $6 / 28(31.4)$ & $3 / 19(15.8)$ & 0.720 \\
\hline Weakness, n (\%) & $14 / 47(29.8)$ & $3 / 28(10.7)$ & $11 / 19(57.9)$ & 0.001 \\
\hline Vertigo, n (\%) & $22 / 47(46.8)$ & $18 / 28(64.3)$ & $4 / 19(21.1)$ & 0.004 \\
\hline Gait disturbance, $\mathrm{n}(\%)$ & $15 / 26(31.9)$ & $10 / 18(55.6)$ & $5 / 8(62.5)$ & 1.000 \\
\hline Number of Posterior Circulation Symptoms Reported, Median (Range) IQR & $4(0-7) 3,5$ & $4(1-7) 4,5$ & $4(0-7) 3,5$ & 0.295 \\
\hline \multicolumn{5}{|l|}{ Signs } \\
\hline Extra-ocular movement abnormality, n (\%) & $2 / 47(4.3)$ & $1 / 28(3.6)$. & $1 / 19(5.3)$ & 1.000 \\
\hline Nystagmus ${ }^{\dagger}, \mathrm{n}(\%)$ & $3 / 10(30.0)$ & $2 / 7(28.6)$ & $1 / 3(33.3)$ & 1.000 \\
\hline Focal motor, n (\%) & $16 / 47(34.0)$ & $7 / 28(25.0)$ & $9 / 19(47.4)$ & 0.112 \\
\hline Dysmetria, n (\%) & $20 / 46(43.5)$ & $13 / 28(46.4)$ & $7 / 18(38.9)$ & 0.615 \\
\hline Gait abnormality ${ }^{\dagger}, \mathrm{n}(\%)$ & $8 / 12(66.7)$ & $7 / 10(70.0)$ & $1 / 2(50.0)$ & 1.000 \\
\hline Number of Posterior Circulation Signs, Median (Range) IQR & $1(0-2) 0,1$ & $1(0-2) 0,1$ & $0(0-2) 0,1$ & 0.131 \\
\hline Total Number of Posterior Circulation Symptoms and Signs, Median (Range) IQR & $5(0-9) 4,6$ & $5(1-8) 4,6$ & $4(0-9) 3,5$ & 0.131 \\
\hline tPA, n (\%) & $5 / 47(10.6)$ & $0 / 28(0.0)$ & $5 / 19(26.3)$ & 0.008 \\
\hline
\end{tabular}

${ }^{\dagger}$ Missing data

stroke registry. Acute ischemic stroke (AIS) patients with a cerebellar infarct confirmed on either CT or MRI were identified for this cross-sectional study. Patients with infarcts in other areas, in addition to their cerebellar infarcts, were excluded. The vascular territory of the cerebellar infarct was determined by a single neurologist reviewing each patient's MRI and then verified using the final neuroradiology report (inter-rater agreement 100\%). Patients with isolated cerebellar infarctions were dichotomized into two groups: (1) those with delayed diagnosis by the first physician who had seen and examined the patient, whether in the outpatient or inpatient setting, and (2) those correctly diagnosed.

Patient demographics, clinical presentation, stroke severity (as measured by the National Institutes of Health Stroke Scale
[NIHSS] score), vascular risk factors, and laboratory values were prospectively collected as part of our stroke registry by trained data abstractors. Common neurological signs and symptoms, many indicative of cerebellar and vestibular dysfunction, were collected retrospectively using a standardized case reporting form, following institutional review board approval. Symptoms included headache, dizziness, vertigo, nausea, vomiting, diplopia, gait abnormality, change in speech, and a history of weakness. Clinical signs collected included dysmetria, abnormal extraocular movements, nystagmus, gait abnormality, and focal motor weakness. The absence of documentation of a sign was interpreted as an examination that was not performed and recorded as missing. 


\section{Table 2: Initial delayed diagnoses.}

\begin{tabular}{l|c}
\hline Initial Misdiagnosis & Number/Percentage of Delayed Diagnoses (n=22) \\
\hline Migraine, $\mathrm{n}(\%)$ & $4(18.2 \%)$ \\
\hline Gastroenteritis, $\mathrm{n}(\%)$ & $4(18.2 \%)$ \\
\hline Upper Respiratory Infection, $\mathrm{n}(\%)$ & $1(4.5 \%)$ \\
\hline Syncope, $\mathrm{n}(\%)$ & $1(4.5 \%)$ \\
\hline Sub-Arachnoid Hemorrhage, $\mathrm{n}(\%)$ & $1(4.5 \%)$ \\
\hline Dehydration, $\mathrm{n}(\%)$ & $1(4.5 \%)$ \\
\hline Mass Lesion, $\mathrm{n}(\%)$ & $1(4.5 \%)$ \\
\hline AVM on CTH, $\mathrm{n}(\%)$ & $1(4.5 \%)$ \\
\hline Hypertensive Urgency, $\mathrm{n}(\%)$ & $2(9.1 \%)$ \\
\hline Attributed to Hemodialysis, $\mathrm{n}(\%)$ & $1(4.5 \%)$ \\
\hline Delirium, $\mathrm{n}(\%)$ & $1(4.5 \%)$ \\
\hline Other Unspecified, $\mathrm{n}(\%)$ & $4(18.2 \%)$ \\
\hline
\end{tabular}

Continuous variables were compared using independent samples t-test or Mann Whitney U, where appropriate. Categorical variables were compared using Chi-square or Fisher Exact, where appropriate. Associations between neurological signs or symptoms and correct initial diagnosis were examined using logistic regression. Marginal effects were used to calculate the change in the probability of having a delayed diagnosis when motor symptoms were present. As this was an exploratory analysis, no adjustments were made for multiple comparisons. ${ }^{9}$ All tests were performed at the $\alpha=0.05$ level.

\section{RESULTS}

A total of 47 individuals with isolated cerebellar infarctions were identified. The mean age was 57.3 years $( \pm 14.6$ years $)$ and $42.6 \%$ were women. Twenty-eight patients $(59.6 \%)$ were in the delayed diagnosis group with $19(40.4 \%)$ in the correct diagnosis group. Among the 28 delayed diagnosis patients, detailed information on where the diagnosis was initially missed was available for twenty patients. Twelve $(60 \%)$ were misdiagnosed in the emergency department (ED), six (30\%) in the outpatient setting, and two (10\%) were misdiagnosed in both an outpatient setting and in the ED. All patients received a CT scan prior to their initial diagnosis followed by an MRI as an inpatient.

Table 1 shows the demographics, vascular risk factors, presenting signs and symptoms, and treatment rates for the initial missed diagnosis and initial correct diagnosis groups. While age, sex, race, stroke severity, and the majority of vascular risk factors were similar between groups, the correct diagnosis group had a significantly higher frequency of dyslipidemia $(31.6 \%$ vs. $3.6 \%$, $\mathrm{p}=0.002$ ). Five subjects in the correct diagnosis group received intravenous (IV) recombinant tissue plasminogen activator (rt-PA) compared to no patients in the delayed diagnosis group (26.3\% vs. $0 \%, \mathrm{p}=0.008$ ). Patients with an initial missed diagnosis more frequently reported vertigo $(64.3 \%$ vs. $21.1 \%, p=0.004)$, while patients with an initial correct diagnosis more frequently reported weakness $(57.9 \%$ vs. $10.7 \%, p=0.001)$, and change in speech $(57.9 \%$ vs. $21.4 \%, \mathrm{p}=0.011)$. No significant differences were observed in the proportion of correct diagnosis and delayed diagnosis patients presenting with dysmetria, abnormal extraocular movements, nystagmus, gait abnormality, or focal motor weakness (Table 1). Interestingly, the median number of posterior circulation symptoms reported, the number of posterior circulation signs on exam, and the total number of posterior circulation symptoms and signs were the same in both groups (Table 1). The two most common diagnoses given to patients who were delayed diagnosis were gastroenteritis and migraine. The initial misdiagnosis was not specified for $25 \%$ of patients (Table 2).

While complaints of weakness appeared to protect patients from delayed diagnosis (odds ratio (OR) 0.087, 95\% CI 0.019-0.393, $\mathrm{p}=0.001$ ), weakness on exam was not protective of delayed diagnosis of cerebellar stroke (OR 0.370, 95\% CI 0.107-1.282, $\mathrm{p}=0.117$ ). These associations remained, even after adjusting for hyperlipidemia, vertiginous symptoms, and change in speech (Table 3). In fact, if a patient complained of weakness, the probability of having a missed diagnosis was decreased by 59 percentage points.

Table 3: The odds of patients with cerebellar stroke who present with complaints of focal weakness or focal weakness on exam of a delayed diagnosis.

\begin{tabular}{l|c|c}
\hline & $\begin{array}{c}\text { Crude Logistic Regression, } \\
\text { Odds Ratio (95\% CI), p value }\end{array}$ & $\begin{array}{c}\text { Adjusted Logistic Regression*, } \\
\text { Odds Ratio (95\% CI), p value }\end{array}$ \\
\hline Complaints of focal weakness (symptom) & $0.087(0.019-0.393)$ & $0.066(0.009-0.479)$ \\
$\mathrm{p}=0.007$
\end{tabular}

*Adjusted for significant differences noted in Table 1 (hyperlipidemia, symptoms of vertigo, complaints of change in speech) 


\section{DISCUSSION}

The diagnosis of cerebellar infarctions can be challenging, as the commonly associated clinical signs and symptoms and the unfound reliance on a negative CT $\operatorname{scan}^{10}$ may not necessarily alert a physician to a stroke. Recognition of these manifestations may aid in early intervention with thrombolysis or secondary prevention of a subsequent stroke. The delayed diagnoses that have been commonly associated with those who actually had a cerebellar stroke vary from migraine, primary gastrointestinal diagnoses and vestibular syndromes. ${ }^{8}$ To this list, we also found that physicians incorrectly diagnose cerebellar infarcts with the following medical conditions: upper respiratory tract infections, hypertensive urgency, sub-arachnoid hemorrhage, dehydration and others (Table 2).

We attempted to identify those factors which are associated with a correct diagnosis. Prior reports suggest that $<1 \%$ of patients with true vertebrobasilar ischemia have only a single presenting symptom or sign. ${ }^{8,11,12}$ Patients with known risk factors for stroke or other vascular events, such as dyslipidemia, and those who presented with a history of any weakness, regardless if weakness was found on examination were more likely to have a correct diagnosis. This may be because the common understanding of a stroke, among physicians, is that it occurs in individuals who have vascular risk factors and present with a component of weakness. The non-specificity of symptoms such as headache, nausea, and vomiting was apparent in our population, as these symptoms were found in similar frequency in both groups. We did not find any signs associated with a correct diagnosis or a delayed diagnosis; which may be due to the low number of patients evaluated for these important clinical findings.

More patients who were correctly diagnosed received rt-PA. The most common reason that more patients in the correct diagnosis group did not receive rt-PA was because they presented out of the time window. It is possible that we were unable to detect the statistical significance of rt-PA and its relationship to outcome secondary to our small sample size, as larger phase three randomized control trials have clearly demonstrated the benefit of rt-PA in acute ischemic stroke. ${ }^{13,14}$

\section{LIMITATIONS}

Our study is limited by its retrospective nature, small sample size and the experience of a single center. In addition, we only studied patients admitted to our institute, and do not know how many patients may have been misdiagnosed in our ED, and went to a different hospital for a subsequent evaluation. Even though the NIHSS was similar between those who were delayed diagnosis and those who were correctly diagnosed, it is still plausible that the patients who returned after being initially misdiagnosed, had more severe signs and symptoms that were not captured by the NIHSS, prompting them to return to the ED. Furthermore, the data collection and analysis of the associated signs and symptoms depended on the physician performing those specific examinations and recording the patient's signs and symptoms. For example, only 12 patients $(25 \%)$ were assessed for gait and only 4 patients $(8.3 \%)$ had documented evidence that nystagmus was present or absent. It is possible that if these signs were checked in all patients that they may have had an association with a delayed diagnosis or a correct diagnosis.

\section{CONCLUSIONS}

Patients with an isolated cerebellar infarction often present with symptoms that may not be captured on the routine outpatient or emergency medicine evaluation. The findings from this study raise concern that acute cerebellar infarction needs to be considered when patients present with acute non-specific symptoms. Recent clinical tools have been developed to differentiate cerebellar strokes from symptoms which may be due to a vestibular syndrome. ${ }^{15}$ However, critical components of the neurological examination are often omitted, such as the assessment of nystagmus and gait, which are imperative to diagnose a cerebellar infarction. A thorough neurological examination may increase clinical suspicion of an ischemic stroke, and should prompt consideration to obtain a MRI, or transfer to facilities with emergent MRI capability.

\section{REFERENCES}

1. Bogousslavsky J, Van Melle G, Regli F. The Lausanne Stroke Registry: analysis of 1,000 consecutive patients with first stroke. Stroke. 1988;19:1083-92.

2. Kumral E, Kisabay A, Atac C, et al. Spectrum of the posterior inferior cerebellar artery territory infarcts. Clinical-diffusionweighted imaging correlates. Cerebrovasc Dis. 2005;20:370-80.

3. Kumral E, Kisabay A, Atac C. Lesion patterns and etiology of ischemia in the anterior inferior cerebellar artery territory involvement: a clinical-diffusion weighted MRI study. Eur J Neurol. 2006;13:395-401.

4. American Heart Association. Heart Disease and Stroke Statistics, 2010 Update. Available from: http://circ.ahajournals.org/content/ 121/7/e46.extract

5. Edlow JA, Newman-Toker DE, Savitz SI. Diagnosis and initial management of cerebellar infarction. Lancet Neurol. 2008 Oct7 (10):951-64.

6. Chalela JA, Kidwell CS, Nentwich LM, et al. Magnetic resonance imaging and computed tomography in emergency assessment of patients with suspected acute stroke: a prospective comparison. Lancet. 2007;369:293-8.

7. Simmons Z, Biller J, Adams HP, et al. Cerebellar infarction: comparison of computed tomography and magnetic resonance imaging. Ann Neurol. 1986;19:291-3.

8. Savitz SI, Caplan LR, Edlow JA. Pitfalls in the diagnosis of cerebellar infarction. Acad Emerg Med. 2007;14(1):63-8.

9. Bender R, Lange S. Adjusting for multiple testing-when and how? J Clin Epidemiol. 2001;54:343-9.

10. Stanton VA, Hsieh YH, Camargo CA Jr, et al. Overreliance on symptom quality in diagnosing dizziness: results of a multicenter survey of emergency physicians. Mayo Clin Proc. 2007;82:1319-28.

11. Savitz SI, Caplan LR. Vertebrobasilar disease. N Engl J Med. 2005;352:2618-26.

12. Kerber KA, Brown DL, Lisabeth LD, Smith MA, Morgenstern LB. Stroke among patients with dizziness, vertigo, and imbalance in the emergency department: a population-based study. Stroke. 2006;37:2484-7.

13. The National Institute of Neurological Disorders and Stroke rt-PA Stroke Study Group. Tissue plasminogen activator for acute ischemic stroke. N Engl J Med. 1995;333:1581-7.

14. Hacke W, Kaste M, Bluhmki E, et al. ECASS Investigators. Thrombolysis with alteplase 3 to 4.5 hours after acute ischemic stroke. N Engl J Med. 2008;359:1317-29.

15. Kattah JC, Talkad AV, Wang DZ, et al. HINTS to diagnose stroke in the acute vestibular syndrome stroke. 2009;40:1-8. 